\title{
Efficiency of carbon nanotubes water based nanofluids as coolants
}

\author{
Salma Halelfadl ${ }^{\text {a }}$, Thierry Maré ${ }^{\text {a }}$ Patrice Estellé ${ }^{\text {b,* }}$ \\ a LGCGM EA3913, Equipe Matériaux et Thermo-Rhéologie, Université Rennes 1, IUT de \\ Saint-Malo, Rue de la Croix Désilles, CS51713, 35417 Saint-Malo Cedex, France \\ b LGCGM EA3913, Equipe Matériaux et Thermo-Rhéologie, Université Rennes 1, IUT de \\ Rennes, 3 rue du Clos Courtel, BP 90422, 35704 Rennes Cedex 7, France
}

\footnotetext{
* Author to whom correspondence should be addressed.

Electronic mail: patrice.estelle@univ-rennes1.fr

IUT de Rennes, 3 rue du Clos Courtel, BP 90422,

35704 Rennes Cedex 7, France

Tel: $+33(0) 23234200$

Fax: +33 (0) 223234051
}

\begin{abstract}
:
The thermo-physical properties of water-based nanofluids containing carbon nanotubes, stabilized by SDBS as surfactant, are experimentally studied. The effect of low nanoparticle volume fraction, ranging from $0.0055 \%$ to $0.278 \%$, on density, thermal conductivity and viscosity of nanofluids is investigated for temperature range of $20^{\circ} \mathrm{C}$ to $40^{\circ} \mathrm{C}$. Enhancement in density, thermal conductivity and viscosity of nanofluids with volume fraction in nanotubes is shown in comparison to base fluids and modelled from simple theoretical relationships. The influence of temperature on the thermo-physical properties of tested nanofluids is also discussed, as well as the shear rate dependence on the nanofluids viscosity. Finally, the efficiency of the tested nanofluids as cooling fluids is evaluated under laminar and turbulent flows regimes from the thermo-physical values previously determined. This may be helpful for using these nanofluids in real cooling systems.
\end{abstract}

Keywords: Heat transfer efficiency, nanofluids, CNT, density, thermal conductivity, viscosity, coolants 


\section{Nomenclature}

L length of nanotubes

$\mathrm{d}$ average diameter of nanotubes

$r$ aspect ratio of nanotube, with $r=L / d$

$\rho$ density, $\mathrm{kg} / \mathrm{m}^{3}$

$\mathrm{k}$ thermal conductivity, $\mathrm{W} / \mathrm{m} . \mathrm{K}$

$\mu$ viscosity, Pa.s

$\mathrm{C}_{\mathrm{p}}$ specific heat, J/kg.K

$\phi$ nanoparticle volume fraction

$\mathrm{C}_{\mathrm{k}}$ thermal conductivity enhancement coefficient

$\mathrm{C}_{\mu}$ viscosity enhancement coefficient

\section{Subscripts}

bf base fluid

nf nanofluid

np nanoparticle

s surfactant

\section{Introduction}

In industrial, transport and building sectors, heat transport through engineered heating or cooling systems is used. Thus, there is a need to achieve compact systems, energy saving and therefore less generators of greenhouse gases. So, new strategies for industrial world have to be developed to improve the thermal behavior of fluids used in heat exchangers.

It is now well established that the thermal performances of conventional working fluids in heat exchangers, such as water, ethylene glycol, oil, etc, can be enhanced by introducing nanoparticles with high thermal properties in low volume fraction within these fluids, leading to the concept of "nanofluids". Some applications of nanofluids and their ability to enhance the heat transfer have been previously reported [1-6]. Although the concept of nanofluids appears straightforward, it contains a high complexity due to physical mechanisms involved. Thus, many researches have been devoted to provide a better understanding of these 
mechanisms, and thereby developed a best performing heat transfer fluids [7-9]. Many research groups experimentally reported that the thermal properties of carbon nanotubes CNT suspensions are much higher than those of other nanoparticles with the same volume fraction [10-12]. In fact, among many materials of nanoparticles, carbon is very promising due to their high thermal, electrical and mechanical properties. A carbon nanotube can be composed of a single-wall (SWCNT) or winding multi-wall (MWCNT). The double-walled nanotubes (DWCNT) are a particular case between SWCNT and MWCNT. They are generally functionalized to improve their solubility and stabilized by a surfactant within the base fluid to prevent agglomeration and sedimentation $[13,14]$.

The addition of CNT improves the thermal conductivity of nanofluids but it can also increase the dynamic viscosity and affect the density and the heat capacity. This shows that these properties are closely correlated. In fact, a significant increase in viscosity can lead to a significant pressure drop which can reduce the practical benefits of nanofluids in some industrial applications $[15,16]$.

Several studies have been reported on the thermo-physical properties of CNT based nanofluids and show a considerable effect compared to the base fluid, as reviewed by Philip and Shima [17]. This enhancement is mainly governed by the volume fraction in nanotubes and the temperature. Ding et al. [18] found that thermal conductivity of CNT based nanofluid increases significantly with the temperature by $15 \%$ at $20^{\circ} \mathrm{C}, 30 \%$ at $25^{\circ} \mathrm{C}$ and by $79 \%$ at $40^{\circ} \mathrm{C}$ at the same volume fraction. Meng et al. [19] showed that the relative thermal conductivity of CNT based nanofluid is independent of temperature for temperature range from 15 to $55^{\circ} \mathrm{C}$. These results are consistent with those found by $\mathrm{Yu}$ et al. [20] and Chen et al. [21]. The effect of surfactant, aspect ratio of nanotubes, and the presence of nanoclusters on thermal conductivity of CNT nanofluids were also investigated by [22-27].

The viscosity of CNT nanofluids was studied in [25-33]. These authors mainly reported a shear thinning behaviour of these nanofluids which depends on the volume fraction of nanotubes, the aspect ratio of nanotubes, dispersion state of nanotubes, the presence and type of surfactant and the temperature. The shear thinning behaviour of CNT nanofluids is also linked to pre-treatments applied to the nanofluids before the measurement such as ultrasonication [26,27] and preshear [32]. Newtonian behavior for MWCNTs dispersed in silicone oil, glycerol and water was reported by Chen et al. [34] for all concentrations and temperatures tested. 
The density and specific heat of CNT nanofluids are rarely investigated from experiments. However, these properties are included in the energy equation, and need to be determined in a rigorous way. The addition of CNTs usually results in an increase of density and a relative decrease of the specific heat of nanofluid due to the lower specific heat of CNTs compared to the base fluid. The density of nanofluids is often evaluated from the theoretical prediction of mixing theory [35]. With specific heat, the assumption of thermal equilibrium between the particles and the base fluid is generally assumed [36].

Kumaresan and Velraj [37] have measured experimentally the density of MWCNT dispersed in a mixture of water and ethylene glycol. According to their results, the density of the nanofluid increases with the volume fraction of particles, and the deviation between the mixing theory and experimental measurements is about $0.4 \%$ for the volume fraction of $0.15 \%, 0.9 \%$ for $0.3 \%$ and $1 \%$ for $0.45 \%$. Pakdamana et al. [38] found a maximum deviation between the mixing theory and experimental measurements of aqueous MWCNT based nanofluids about $1 \%$ for $0.4 \%$ mass fraction. They also observed the decrease of specific heat about $42 \%$ due to the addition of MWCNT. Kumaresan and Velraj [37] have shown experimentally that the mixing theory [35] allows reproducing their experimental results with a relative error about $8 \%$ for a volume fraction of $0.15 \%$ and about $3 \%$ for $0.45 \%$

As reported above, the addition of CNT to the base fluid can affect significantly the thermo physical properties. Consequently, it is necessary to envisage a global approach of thermophysical properties of nanofluids to evaluate best performing heat transfer with these fluids. Hence, we investigated in this paper the effect of low nanoparticle volume fraction and temperature on the thermo-physical properties for water-based nanofluids containing CNT stabilized by SDBS as surfactant. First, we present the nanofluids used in this study as well as the experiments performed to measure the density, the thermal conductivity and the viscosity of nanofluids. Then, experimental results are presented and discussed. Based on the thermophysical values previously determined, the efficiency of the tested nanofluids as coolants was finally evaluated under laminar and turbulent flow regimes to assess the performance of the tested nanofluids in energy systems and heat exchangers. 


\section{Materials and experimental methods}

\subsection{Nanofluids}

As reported in [33], a starting CNT water-based suspension was provided by Nanocyl (Belgium). According to Nanocyl's specification, this suspension consists of MWCNTs (carbon purity 90\%) dispersed from ultrasonication in de-ionized water and stabilized by sodium dodecyl benzene sulfonate (SDBS) as surfactant. The dimensions of the nanotubes are $1.5 \mu \mathrm{m}$ in average length $\mathrm{L}$ and $9.2 \mathrm{~nm}$ in average diameter $\mathrm{d}$ respectively. This leads to an average aspect ratio $\mathrm{r}=\mathrm{L} / \mathrm{d} \approx 163$. The density of the nanotubes is $1800 \mathrm{~kg} / \mathrm{m}^{3}$. The weight fraction in nanotubes of the starting suspension is $1 \%$. This leads to a volume fraction of $0.55 \%$. The quantity of surfactant in the starting suspension represents $2 \%$ of the total weight of the nanosuspension. The base fluid, defined as a mixture of de-ionized water and SDBS, was also independently prepared and provided by Nanocyl.

Four different nanofluid samples were prepared with the volume fraction of $0.278,0.111$, 0.055 and $0.00555 \%$ respectively. For these nanofluids, SDBS/CNT weight ratio still remains constant to 2. They were obtained from the dilution with de-ionized water of the starting suspension, followed by continuously mechanical stirring for $30 \mathrm{~min}$. Mechanical stirring was also repeated $24 \mathrm{~h}$ later for $30 \mathrm{~min}$. Then, the nanofluids were stored in a container at ambient temperature before being used for experimental measurements. The initial base fluid was also

diluted to produce the base fluids corresponding to the different nanofluids previously prepared. It is worth noting that we selected low volume fraction of CNTs to reduce the viscosity of nanofluids, as the addition of nanoparticles can penalize the practical use of nanofluids in heat exchangers due to flow resistance and increase in pumping power.

\subsection{Experiments}

The thermo physical properties of the tested nanofluids were evaluated in this work for three operating temperatures 20,30 and $40^{\circ} \mathrm{C}$. The density, the thermal conductivity and the viscosity of the fluids were experimentally measured following the procedures described in the following.

The density measurements of nanofluids were performed with an Anton PAAR DMA vibrating tube densimeter connected to cell 602. Each measurement was performed in five 
replicates. The densimeter contains a vibrating glass tube which can be excited harmonically by an electronic vibration circuit. This electronic vibration circuit activates and sustains a continuous vibration to the tube with natural frequency. The principle of the vibrating-tube densimeter relies on a fixed relation between the natural frequency of the vibrating-tube and the density of fluid contained in the tube. The frequency of the oscillation is affected by the mass of the oscillator, and therefore the density of the sample. The temperature in the cell is stabilized by a cryothermostat able to ensure accuracy up to $0.01 \mathrm{~K}$. The calibration of the densimeter was preliminary performed using pure water and dry air. This leads to a precision measurement about $1.10^{-5} \mathrm{~g} / \mathrm{cm}^{3}$.

The density of SDBS in powder form was independently measured from the pycnometer method for the three operating temperatures, using a $100 \mathrm{ml}$ flask, a precision balance and distilled water and toluene as liquids. The accuracy of the measurement was controlled from the measured density of distilled water and toluene. As example, the density of distilled water and toluene at $20^{\circ} \mathrm{C}$ was evaluated to $1.03 \mathrm{~g} . \mathrm{cm}^{3}$ and $0.806 \mathrm{~g} . \mathrm{cm}^{3}$. This agrees well with theoretical values, with a maximum deviation of $3.5 \%$ for distilled water and $0.5 \%$ with toluene. Moreover, it was observed that the density of SDBS decreases by $1.18 \mathrm{g.cm}$ to 1.04 g. $\mathrm{cm}^{3}$ when the temperature increases by $20^{\circ} \mathrm{C}$ to $40^{\circ} \mathrm{C}$.

The thermal conductivity of nanofluids and base fluids was measured using a KD2 Pro thermal property analyzer (Decagon Devices Inc.) based on the transient hot wire. The experimental set-up for thermal conductivity measurement was previously used and shown in [39]. Both the sample and the probe were maintained $30 \mathrm{~min}$ at the working temperature before each experiment. Then, an average of over ten measurements was performed to reduce the experimental errors. The accuracy and reliability of the measurement were carefully checked with distillated water, used as calibration liquid for temperatures range from 20 to $50^{\circ} \mathrm{C}$. The experimental results of water were found to be in quite good agreement with literature values of thermal conductivity of this fluid. The standard relative deviation was typically less than $3.5 \%$.

As reported in [33], rheological measurements of nanofluid samples were performed using a stress controlled rheometer (Malvern Kinexus Pro [40]) in a cone and plate configuration under controlled temperature. The radius and the angle of the conical geometry were $60 \mathrm{~mm}$ 
and $1^{\circ}$ respectively. In all experiments, the nanofluid was carefully loaded between the cone and plate geometry to avoid air bubbles, and the excess fluid removed. The temperature control is ensured and provided through the Peltier system located below the lower plate, which is accurate to within $0.01{ }^{\circ} \mathrm{C}$. Thermal clovers were also used to ensure constant temperature within the sample gap. The sample was allowed to equilibrate at the working temperature for $5 \mathrm{~min}$ before starting the viscosity measurement. A new sample was used for each measurement and both cone and plate were cleaned between each measurement. Then, without any preshear, the viscosity of the nanofluids was measured by imposing a logarithmic stress ramp under steady-state conditions with maximum step duration of 180 s. Once a steady-state flow was achieved and maintained for $10 \mathrm{~s}$, the shear rate was measured. As reported in our previous works $[32,33]$, the shear stress range was preliminary determined to ensure steady-state flow at low shear stress, and to avoid instability due to turbulent flow and sample ejection at high shear stress, as well as to reach a shear rate of $1000 \mathrm{~s}^{-1}$ for each fluid. A suitable expression can be used to know the Reynolds number with cone and plate geometry [41]:

$$
R_{e} \approx \frac{\dot{\gamma} \rho_{n f}}{\mu_{n f}}\left(\frac{\pi R \alpha}{180}\right)^{2}
$$

Where $\rho_{\mathrm{nf}}$ is the density of nanofluids $\left(\mathrm{kg} / \mathrm{m}^{3}\right), \dot{\gamma}$ is the shear rate (in $\left.1 / \mathrm{s}\right), \mu_{\mathrm{nf}}$ is the viscosity of nanofluid (in Pa.s), $\alpha$ is the cone angle (in ${ }^{\circ}$ ) and $\mathrm{R}$ is the cone and plate diameter (in $\mathrm{m}$ ). As reported thereafter, the values of Reynolds number varies between 2 and 450 following the shear rate, the volume fraction and the temperature. This means that rheological measurements are well performed under laminar flow regime.

The experiments were also repeated at least once to both verify the repeatability of the shear viscosity measurement and the suspension stability with time. Following the same experimental procedure, the viscosity of the base fluids corresponding to the tested nanofluids was also measured. The uncertainty in experimental measurement is less than $4 \%$ within the shear rate range investigated [33].

\section{Results and discussion}




\subsection{Thermophysical properties of nanofluids: effect of nanoparticle volume fraction and temperature}

\subsubsection{Density}

The measured densities of the nanofluids are presented in figure 1 for the operating temperatures of 20,30 and $40^{\circ} \mathrm{C}$ respectively and for all tested volume fractions. Moreover, the predicted values of nanofluids density obtained from the mixing theoretical correlation [35] are presented in figure 1 considering the nanoparticles and the base fluid. A similar equation is derived taking also into account the influence of the surfactant, see equation (2).

$$
\rho_{n f}=\left(1-\phi-\phi_{s}\right) \rho_{w}+\phi \rho_{n p}+\phi_{s} \rho_{s}
$$

Where $\phi$ is the volume fraction in nanoparticles and $\phi_{\mathrm{s}}$ is the volume fraction of surfactant. $\rho_{\mathrm{nf}}$, $\rho_{\mathrm{w}}, \rho_{\mathrm{np}}$, and $\rho_{\mathrm{s}}$ denote respectively the density of nanofluid, the density of de-iozined water, the density of nanoparticles and the density of the surfactant.

It is shown from figure 1 that, for each tested temperatures, the density of nanofluids is quite constant under the experimental uncertainty. As expected, figure 1 also shows that the measured density of nanofluids increases as the nanoparticle volume fraction increases for all tested operating temperatures. A similar trend is reported for the theoretical correlations which closely matched with the experimental data. This infers that mixing theoretical correlation can predict the density of tested nanofluids for the volume fraction in nanoparticles investigated due to the low content in surfactant. For higher volume fraction in nanoparticles and surfactant, it is expected that equation (2) can predict the density of nanofluids considering well the base fluid as a mixture of surfactant and de-ionized water.

Based on the previous results, the evolution of the relative density of nanofluids, which is defined as that ratio of the nanofluids density to the base fluids density, is presented in figure 2 as a function of nanoparticles volume fraction. Figure 2 shows that the relative density increases quite linearly with increase in tested nanoparticle volume fraction. It can also be 
mentioned that the relative density of nanofluids increases when the temperature increases whatever the tested volume fraction in nanoparticles.

\subsubsection{Thermal conductivity}

Figure 3 reports the thermal conductivity enhancement of nanofluids in comparison with base fluids at the tested volume fractions and temperatures. The thermal conductivity enhancement is defined as $k_{n f} / k_{b f}$ where $k_{b f}$ is the thermal conductivity of the base fluid and $k_{n f}$ is the thermal conductivity of the nanofluid.

Figure 3 shows that thermal conductivity of nanofluids increases as volume fraction and temperature increase. A similar trend was previously reported for a wide class of nanofluids [7-9,17]. Within the range of nanoparticle volume fraction presently investigated, the linear dependence of thermal conductivity enhancement of nanofluids can be simply related to nanoparticle volume fraction by the following empirical-model $[42,43]$.

$$
k_{n f} / k_{b f} \approx 1+C_{k} \phi
$$

Where $C_{k}$ is thermal conductivity enhancement coefficient.

$\mathrm{C}_{\mathrm{k}}$ is here evaluated to 41,70 and 85 at $20^{\circ} \mathrm{C}, 30^{\circ} \mathrm{C}$ and $40^{\circ} \mathrm{C}$ respectively.

\subsubsection{Viscosity}

The main results of viscosity measurement were reported in a previous work [33]. In short, it was shown that the nanofluids with particle concentration of 0.278 and $0.111 \%$ behave as shear thinning fluids. The shear thinning behavior is attributed to the alignment of structural network of nanotubes at the initiation of shear, resulting afterwards in less viscous force. The values of apparent viscosity decrease with the shear rate and the volume fraction in nanoparticles. The shear-thinning region is up to $200 \mathrm{~s}^{-1}$; for higher shear rate, the viscosity tends to a Newtonian plateau.

For lower particle content of 0.055 and $0.0055 \%$, the nanofluids behave in Newtonian manner as the apparent viscosity is quite constant within the shear rate range investigated. It is worth noting that the viscosity of nanofluids with particle content of 0.055 and $0.0055 \%$ is close to 
the viscosity of base fluid. As an example, we report in figure 4 the apparent viscosity of nanofluids at $30^{\circ} \mathrm{C}$. This figure evidences the previous comments. It was also reported in [33] that the base fluids behave as Newtonian fluids for the presently tested nanofluids.

Due to shear-thinning behavior of some nanofluids, the evolution of relative viscosity of nanofluids defined as the ratio of the nanofluid viscosity to the viscosity of the base fluid is here investigated at different shear rate values and for all tested temperatures. So, we have considered a low shear rate value of $20 \mathrm{~s}^{-1}$, an intermediate shear rate of $200 \mathrm{~s}^{-1}$ which corresponds to the transition between shear-thinning and Newtonian behavior of some nanofluids and the maximum shear rate of $1000 \mathrm{~s}^{-1}$ where a Newtonian plateau is achieved. As the relative viscosity of the tested nanofluids is independent of temperature under the experimental uncertainty [33], an average value of relative viscosity of nanofluids is here considered for the three operating temperatures. It is worth nothing that the relative viscosity is temperature independent whatever the shear rate value considered.

The evolution of relative viscosity of nanofluids in function of shear rate and volume fraction is detailed in figure 5. It shows that the viscosity enhancement due to the presence of nanotubes is significant for volume fraction in nanotubes higher than $0.055 \%$ and that the evolution of the relative viscosity is quite linear within the tested volume fraction in nanoparticles, in particular too from a volume fraction higher than $0.055 \%$. It is also observed from figure 5 the influence of shear-thinning behavior of nanofluids, as the enhancement of relative viscosity of nanofluids decrease when the shear rate increases.

A similar empirical model to thermal conductivity enhancement of nanofluids can also be used to predict the relative viscosity enhancement of nanofluids independently of shape and dispersion state of nanoparticles $[42,43]$. It writes as follows

$$
\mu_{n f} / \mu_{b f} \approx 1+C_{\mu} \phi
$$

Where $C_{\mu}$ is viscosity enhancement coefficient, which is here independent on temperature. $\mu_{\mathrm{bf}}$ is the viscosity of the base fluid and $\mu_{\mathrm{nf}}$ is the viscosity of the nanofluid. From equation (4) and figure $5, \mathrm{C}_{\mu}$ is here evaluated to 550,330 and 260 for low shear rate of $20 \mathrm{~s}^{-1}$, intermediate shear rate of $200 \mathrm{~s}^{-1}$ and maximum shear rate of $1000 \mathrm{~s}^{-1}$ respectively. 
According to equation (1), we have also calculated the Reynolds number corresponding to the different shear rates, particle contents and temperatures investigated. These values are reported in Table 1. Because of the rheological properties of the nanofluids, it is observed from Table 1 that the Reynolds number within the cone and plate geometry increases with temperature and shear rate. These values are also enhanced when the volume content in nanoparticles decreases. Table 1 also shows that rheological measurements are performed under laminar flow regime as the maximum Reynolds number is less than 450.

Based on the previous results, the efficiency of the studied nanofluids as coolants is investigated in the following considering the effect of temperature and particle volume fraction, as well as the flow regime.

\subsection{Efficiency of nanofluids in laminar regime}

According to literature $[42,43]$, the use of nanofluids as coolants under laminar flow is beneficial when equation (4) is satisfied.

$$
C_{\mu} / C_{k}<4
$$

For the tested nanofluids, the ratio defined by equation (5) can be calculated from the experimental results reported above. The obtained values are detailed in Table 2 considering the effect of shear rate on the rheological behavior of nanofluids. It is observed from Table 2 that the ratio of viscosity enhancement coefficient to thermal conductivity enhancement coefficient is higher than 4 at $20^{\circ} \mathrm{C}$ whatever the shear rate. This means that at this temperature, the thermal conductivity enhancement is penalized by the viscosity enhancement of the nanofluids, which can increase the pumping power and the pressure drop of these nanofluids in energy systems. When the temperature is increased, Table 2 shows that the nanofluids become efficient in laminar regime for high shear rate at $30^{\circ} \mathrm{C}$ i.e. for Reynolds number ranging from 180 to 330 . At $40^{\circ} \mathrm{C}$, the efficiency of nanofluids is extended to lower shear rate of $200 \mathrm{~s}^{-1}$. This corresponds to Reynolds number ranging from 40 to 450 . 


\subsection{Efficiency of nanofluids in turbulent regime}

Under turbulent flow regime, the heat transfer rate of nanofluids depends on the whole of thermophysical properties of the fluid, and can be evaluated from the Mouromtseff number, $\mathrm{M}_{\mathrm{o}}$ [43]. This number is defined by equation 6. Higher the Mouromtseff number, better the potential of the nanofluid as coolant.

$$
M_{0}=\frac{\rho^{0.8} k^{0.67} C_{p}^{0.33}}{\mu^{0.47}}
$$

Where $\rho, \mathrm{k}, \mathrm{C}_{\mathrm{p}}$, and $\mu$, are respectively the density (in $\mathrm{kg} / \mathrm{m}^{3}$ ), thermal conductivity (in $\mathrm{W} / \mathrm{m} . \mathrm{K}$ ), specific heat (in J/kg.K) and viscosity (in Pa.s) of the nanofluid. As the rheological measurements have been performed in laminar regime, we have considered the viscosity value of nanofluids within the Newtonian plateau in equation (6).

The heat capacity of the fluids was here evaluated from the available theoretical correlation proposed in [36], and described by the equation (7). For this purpose, it is here assumed that SDBS poorly contributes to the heat capacity of nanofluids to be neglected because of the low content in SDBS within the nanofluids. In addition, we have shown above that the density of the nanofluid is not influenced by the presence of surfactant for the tested volume fractions.

$$
C_{p, n f}=\frac{\phi\left(\rho C_{p}\right)_{n p}+(1-\phi)\left(\rho C_{p}\right)_{b f}}{\phi \rho_{n p}+(1-\phi) \rho_{b f}}
$$

Figure 6 shows the specific heat of the nanofluids evaluated from equation (7) for the tested volume fractions and temperatures. Figure 6 indicates a very low decrease of the heat capacity of nanofluids when the volume fraction increases. In addition, the values of figure 6 illustrate a slight effect of temperature. At 30 and $40^{\circ} \mathrm{C}$, the heat capacity of nanofluids is quite identical. The heat capacity of nanofluids seems to be higher at $20^{\circ} \mathrm{C}$. 
From the previous experimental data and both equations (6) and (7), the Mouromtseff number of base fluids and nanofluids was calculated for the tested volume fractions and temperatures. This allows us to evaluate enhancement of Mouromtseff number defined as the ratio of Mouromtseff number of nanofluids to Mouromtseff number of base fluids. It is reported in figure 7. In comparison with laminar regime, the thermal performances of nanofluids in turbulent regime are dependent on both temperature and volume fraction of nanoparticles. Efficiency of nanofluids at $20^{\circ} \mathrm{C}$ is only evidenced for the lower volume fraction tested. When the temperature increases to $30^{\circ} \mathrm{C}$, the efficiency of nanofluids is extended to $0.055 \%$ in volume fraction. At $40^{\circ} \mathrm{C}$, the nanofluids are efficient for volume fractions ranging from $0.0055 \%$ to $0.111 \%$. It is finally observed that the best performance in turbulent regime is obtained at $40^{\circ} \mathrm{C}$ for the nanofluid at lower volume fraction.

\section{Conclusions}

In this study, we experimentally investigated the thermo-physical properties of water-based nanofluids containing carbon nanotubes (CNT) and stabilized by SDBS as surfactant. The influence of particles concentration - from $0.0055 \%$ to $0.278 \%$ - and temperature - from $20^{\circ} \mathrm{C}$ to $40^{\circ} \mathrm{C}$ - on the density, thermal conductivity and viscosity of the nanofluids were presented and discussed. Based on these experimental results, the following conclusions may be drawn for the tested nanofluids:

- The density is independent of temperature and increases with particle volume fraction. A similar trend is reported for the relative density.

- The relative thermal conductivity increases with nanoparticle volume fraction and temperature.

- The relative viscosity of nanofluids is affected by both the increase in nanoparticle volume fraction and shear rate.

Based on the proper determination of these properties, the efficiency of the nanofluids as coolants was evaluated in both laminar and turbulent flow regimes. It was demonstrated that the nanofluids investigated in this paper can be beneficial in energy systems and heat exchangers involving fluid flow following the temperature of the set-up, the volume fraction in nanoparticles and the flow regimes. 
- In laminar regime, the nanofluids become efficient at $30^{\circ} \mathrm{C}$ and for Reynold numbers ranging from 180 to 330 . Increasing the temperature to $40^{\circ} \mathrm{C}$, the efficiency of nanofluids is increased to higher range of Reynold numbers.

- In turbulent regime, the efficiency of the nanofluids is dependant to both the decrease in particle volume fraction and the increase in temperature.

\section{Acknowledgments}

The authors wish to thank Nanocycl Belgium for providing the CNT water based nanofluid.

\section{References}

[1] G. Huminic, A. Huminic, Applications of nanofluids in heat exchangers: A review, Renewable and Substainable Energy Reviews 16 (2012) 5625-5638.

[2] W. Daungthongsuk, S. Wongwises A critical review of convective heat transfer of nanofluids, Renew. Sustain. Energy Reviews 11 (2007) 797-817.

[3] O. Mahian, A. Kianifar, S.A. Kalogirou, I. Pop, S. Wongwises A review of the applications of nanofluids in solar energy, Int. J. Heat Mass Transfer 57 (2013) 582-594.

[4] J.M. Wu, J. Zhao, A review of nanofluid heat transfer and critical heat flux enhancementResearch gap to engineering application, Progress in Nuclear Energy, 66 (2013) 13-24.

[5] S. Nadeem, A. Rehman, M.E. Ali, The boundary layer flow and heat transfer of a nanofluid over a vertical slender cylinder, J. Nanoeng. Nanosystems 226-4 (2012) 165-173.

[6] S. Nadeem, R. Mehmood, N. Sher Akbar, Non-orthogonal stagnation point flow of a nano non-Newtonian fluid towards a stretching surface with heat transfer, Int. J. Heat Mass Transfer, 55 (2013) 3964-3970.

[7] S. Choi , Enhancing thermal conductivity of fluids with nanoparticules, In Developments Applications of Non-Newtonians Flows, D.A. Siginer and H. P. Wang. New-York: Americain Society of Mechanical Engineers, Vol. 66, pp. 99-105, 1995.

[8] X.Q. Wang, A.S. Mujumdar, Heat transfer characteristics of nanofluids: A review, Int. J. Therm. Sci. 46 (2007) 1-19.

[9] D. Wen, S. Lin, S. Vafaei, K. Zhang, Review of nanofluids for heat transfer applications, Particuology 7 (2009) 141-150. 
[10] T. Maré, S. Halelfadl, O. Sow, P. Estellé, S. Duret, F. Bazantay, Comparison of the thermal performances of two nanofluids at low temperature in a plate heat exchanger, Exp. Thermal Fluid Sci. 35/8 (2011) 1535-1543.

[11] M.S. Liu, M.C. Lin, I.T. Huang, C.C. Wang, Enhancement of thermal conductivity with carbon nanotube for nanofluids. Int. Com. Heat Mass Transfer 32 (2005) 1202-1210.

[12] H. Xie, H. Lee, W. Youn, M. Choi, Nanofluids containing multiwalled carbon nanotubes and their enhanced thermal conductivities, J. Appl. Phys. 94 (2003) 4967-4971.

[13] H. Wang, Dispersing carbon nanotubes using surfactants, Curr. Opinion Coll. Interface Sci. 14 (2009) 364-371.

[14] L. Vaisman, H.D. Wagner, G. Marom, The role of surfactants in dispersion of carbon nanotubes, Adv. Coll. Int. Sci. 128-130 (2006) 37-46.

[15] S. Ferrouillat, A. Bontemps, J.P. Ribeiro, J.A. Gruss, O. Soriano, Hydraulic and heat transfer study of $\mathrm{SiO} 2 /$ Water nanofluids in horizontal tubes with imposed wall temperature boundary conditions, Int. J. Heat Fluid Flow 32 (2011) 424-439.

[16] J.P. Mayer, T.J. Mc Krell, K. Grote, The influence of multi-walled carbon nanotubes on single phase heat transfer and pressure drop characteristics in the transitional flow regime of smooth tubes, Int. J. Heat Mass Transfer 58 (2013) 597-609.

[17] J. Philip, P.D. Shima, Thermal properties of nanofluids, Adv. Coll. Interface Sci. 183184 (2012) 30-45.

[18] Y. Ding, H. Alias, D. Wen, R.A. Williams, Heat transfer of aqueous suspensions of carbon nanotubes (CNT nanofluids), Int. J. Heat Mass Transfer 49 (2006) 240-250.

[19] Z. Meng, D. Wu, L. Wang, H. Zhu, Q. Li, Carbon nanotube glycol nanofluid: Photothermal properties, thermal conductivities and rheological behavior, Particuology 10 (2012) 614-618.

[20] W. Yu, S.U.S. Choi, The role of interfacial layers in the enhanced thermal conductivity of nanofluids: a renovated Maxwell model, J. Nanoparticle Res. 5 (2003) 167-171.

[21] L. Chen, H. Xie, Y. Li, W. Yu, Nanofluids containing carbon nanotubes treated by mechanochemical reaction, Thermochim. Acta, 477 (2008) 4-21.

[22] D.S. Wen, Y.L. Ding, Effective thermal conductivity of aqueous suspensions of carbon nanotubes (nanofluids), J. Thermophys. Heat Transfer 18 (2004) 481-485.

[23] M.J. Assael, I.N. Mataxa, J. Arvanitidis, D. Christophilos, C. Lioutas, Thermal conductivity enhancement in aqueous suspensions of carbon multi-walled and double-walled nanotubes in the presence of two different dispersants, Int. J. Thermophys. 26 (2005) 647664. 
[24] A. Nasiri, M. Shariaty-Niasar, A. Rashidi, A. Amrollahi, R. Khodafarin, Effect of dispersion method on thermal conductivity and stability of nanofluid, Exp. Thermal Fluid Sci. 35 (2011) 717-723.

[25] T.X. Phuoc, M. Massoudi, R.H. Chen, Viscosity and thermal conductivity of nanofluids containing carbon nanotubes stabilized by chitosan, Int. J. Thermal Sci. 50 (2011) 12-18.

[26] P. Garg, L.A. Jorge, C. Marsh, T.A. Carlson, D.A. Kessler, K. Annamalai, An experimental study on the effect of ultrasonication on viscosity and heat transfer performance of multi-wall carbon nanotube-based aqueous nanofluids, Int. J. Heat Mass Transfer 52 (2009) $5090-5101$.

[27] Y. Yang, E.A. Grulke, Z.G. Zhanh, G. Wu, Thermal and rheological properties of carbon nanotube-in-oil dispersions, J. Appl. Phys. 99 (2006) 114307.

[28] A. Indhuja, K.S. Suganthi, S. Manikandan, K.S. Rajan Viscosity and thermal conductivity of dispersions of gum arabic capped MWCNT in water: Influence of MWCNT concentration and temperature, J. Taiwan Institute Chem. Eng. 44 (2013) 474-479.

[29] Q. Chen, C. Saltiel, S. Manickavasagam, L.S. Schadler, R.W. Siegel, H. Yang, Aggregation behavior of single-walled carbon nanotubes in dilute aqueous suspension, J. Colloid Interface Sci. 280 (2004) 91-97.

[30] J. Ponmozhi, F.A.M.M. Gonçalves, A.G.M. Feirrera, I.M.A Fonseca , S. Kanagaraj, M. Martins, M.S.A. Oliveira, Thermodynamic and transport properties of CNT water based nanofluids, J. Nano Res. 11 (2010) 101-106.

[31] B. Aladag, S. Halelfadl, N. Doner, T. Maré, S. Duret, P. Estellé, Experimental investigations of the viscosity of nanofluids at low temperatures, App. Energy 97 (2012) 876880.

[32] P. Estellé, S. Halelfadl, N. Doner, T. Maré, Shear flow history effect on the viscosity of carbon nanotubes water based nanofluid, Curr. Nanosci., 9/2 (2013) 225-230.

[33] S. Halelfadl, P. Estellé, B. Aladag, N. Doner, T. Maré, Viscosity of carbon nanotubes water-based nanofluids: Influence of concentration and temperature, Int. J. Thermal Sci. 71 (2013) 111-117.

[34] L. Chen, H. Xie, W. Yu, Y. Li, The rheological behaviors of nanofluids containing multiwalled carbon nanotube, J. Disp. Sci. Tech. 32 (2011) 550-554.

[35] B.C. Pak, Y.I. Cho, Hydrodynamic and heat transfer study of dispersed fluids with submicron metallic oxide particles, Exp. Heat Transfer 11 (1998) 151-170. 
[36] H. O’Hanley, J. Buangiorno, T. McKrell, L. W. Hu, Measurement and model validation of nanofluid specific heat capacity with Differential Scanning Calorimetry, Adv. Mech. Eng. (2012) ID 181079.

[37] V. Kumaresan, R. Velraj, Experimental investigation of the thermo-physical properties of water-ethylene glycol mixture based CNT nanofluids, Thermo. Acta 545 (2012) 180-186.

[38] M.F. Pakdamana, M.A. Akhavan-Behabadi, P. Razi, An experimental investigation on thermo-physical properties and overall performance of MWCNT/heat transfer oil nanofluid flow inside vertical helically coiled tubes, Exp. Thermal Fluid Sci. 40 (2012) 103-111.

[39] S. Halelfadl, A.M. Adham, N. Mohd-Ghazali, T. Maré, P. Estellé, R. Ahmad, Optimization of thermal performance and pressure drop of a rectangular microchannel heat sink using aqueous carbon nanotubes based nanofluid, App. Thermal Eng. 62/2 (2014) 492499.

[40] http://www.malvern.com/labeng/products/kinexus/kinexus_rotational_rheometer.htm, october 2013

[41] J.W. Goodwin, R.W. Hughes, Rheology for Chemists: An Introduction, Royal Society of Chemistry Publishing, 2008 - 264 pages.

[42] R. Prasher, D. Song, J. Wang, P. Phelan, Measurements of nanofluid viscosity and its implications for thermal applications, App. Phys. Lett. 89 (2006) 133108.

[43] E.V. Timofeeva, J.L. Routbort, D. Singh, Particle shape effect on thermophysical properties of alumina nanofluids, J Appl. Phys. 106 (2009) 014304. 


\section{Figure Captions}

Figure 1. Density of nanofluids in function of nanoparticle volume fraction

Figure 2. Density enhancement of nanofluids in function of nanoparticle volume fraction and temperature

Figure 3. Thermal conductivity enhancement of nanofluids in function of nanoparticle volume fraction and temperature

Figure 4. Apparent shear viscosity of nanofluids at $30^{\circ} \mathrm{C}$

Figure 5. Viscosity enhancement of nanofluids in function of nanoparticle volume fraction and shear rate

Figure 6. Specific heat of the nanofluids in function of nanoparticle volume fraction and temperature

Figure 7. Enhancement of Mouromtseff number of the nanofluids in function of nanoparticle volume fraction and temperature

\section{Table Captions}

Table 1. Reynolds number within the cone and plate geometry for the studied nanofluids: Influence of shear rate, particle content and temperature

Table 2. Ratio of viscosity enhancement coefficient to thermal conductivity enhancement coefficient in function of temperature. 


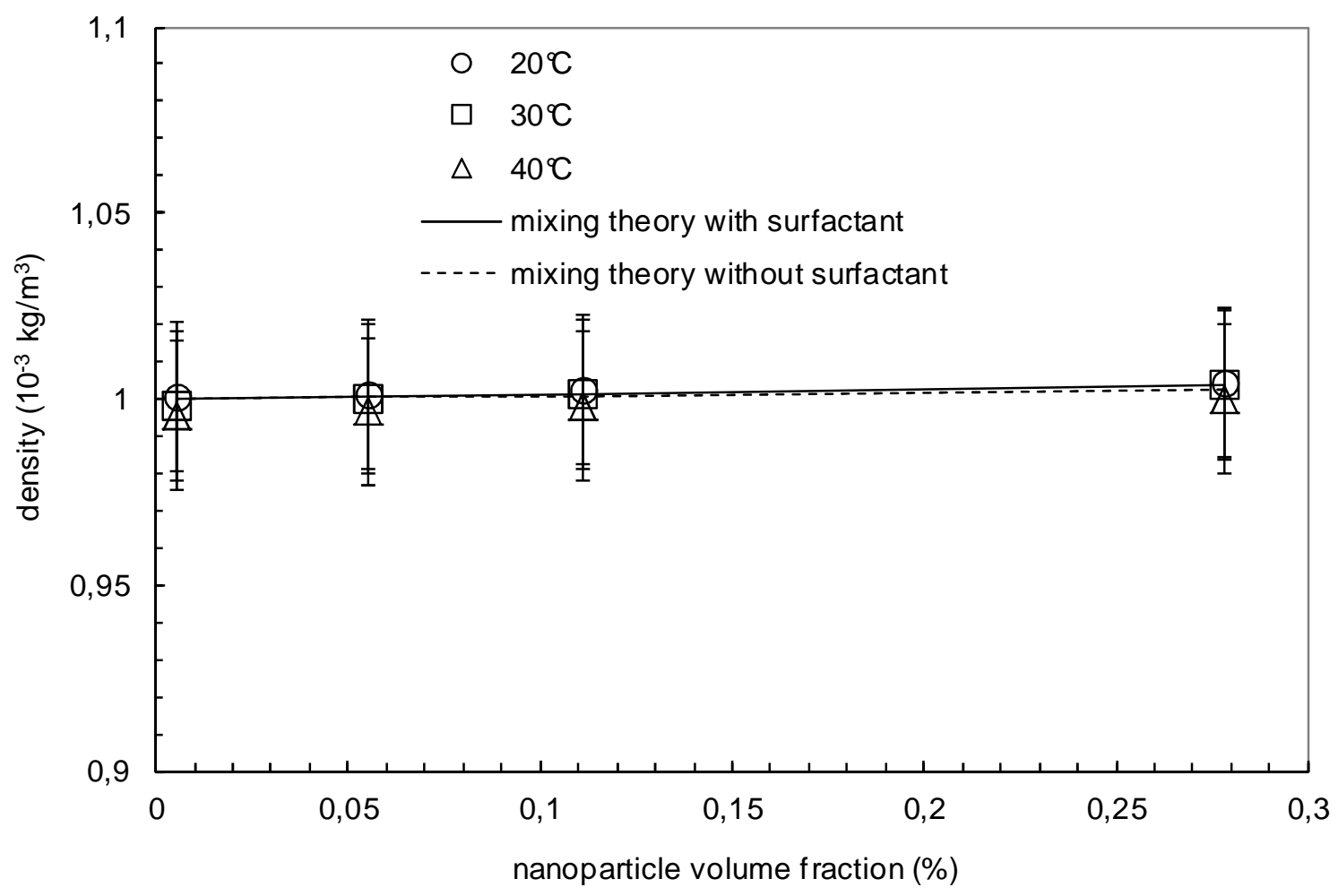

Figure 1. Density of nanofluids in function of nanoparticle volume fraction 


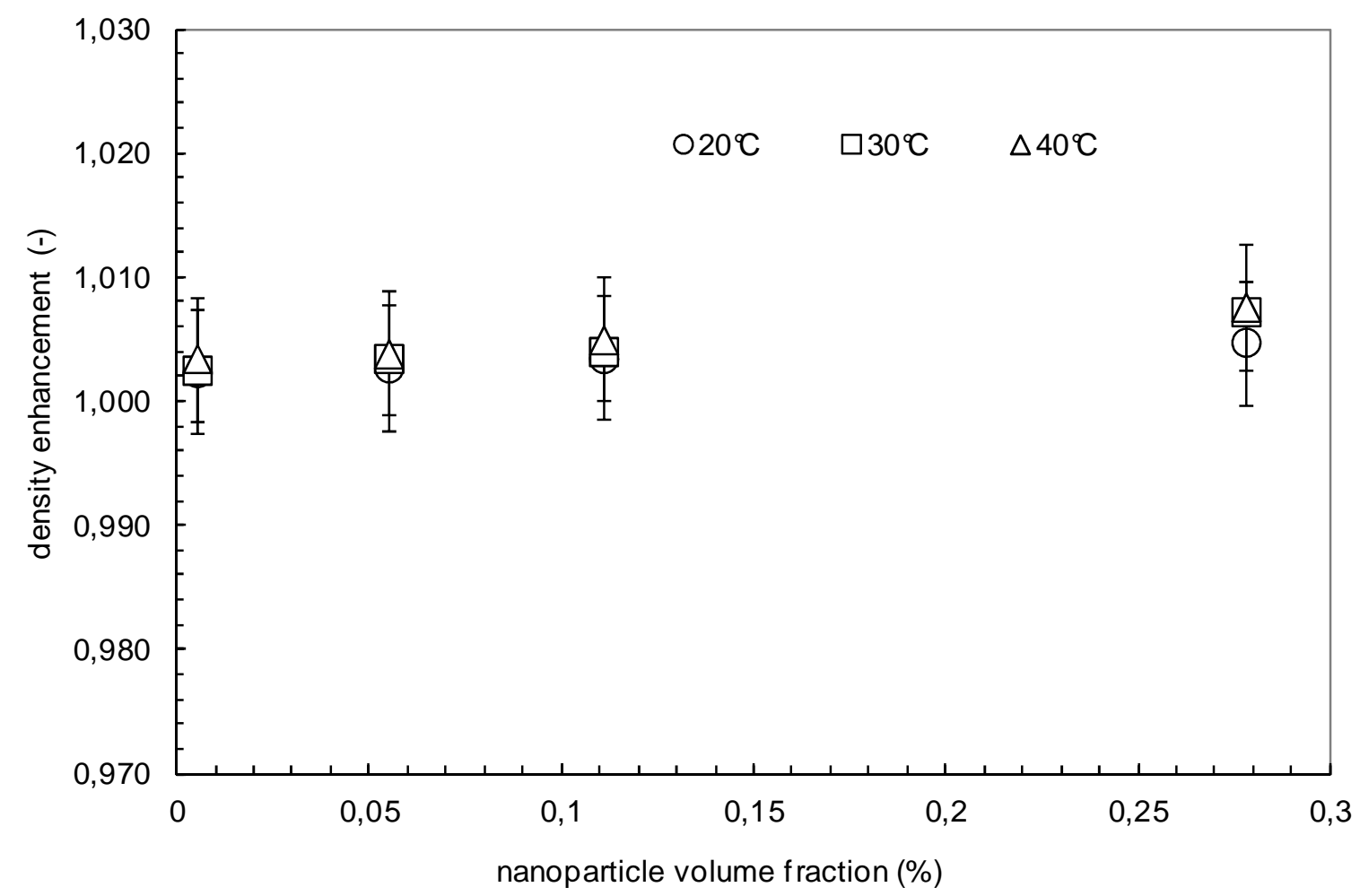

Figure 2. Density enhancement of nanofluids in function of nanoparticle volume fraction and temperature 


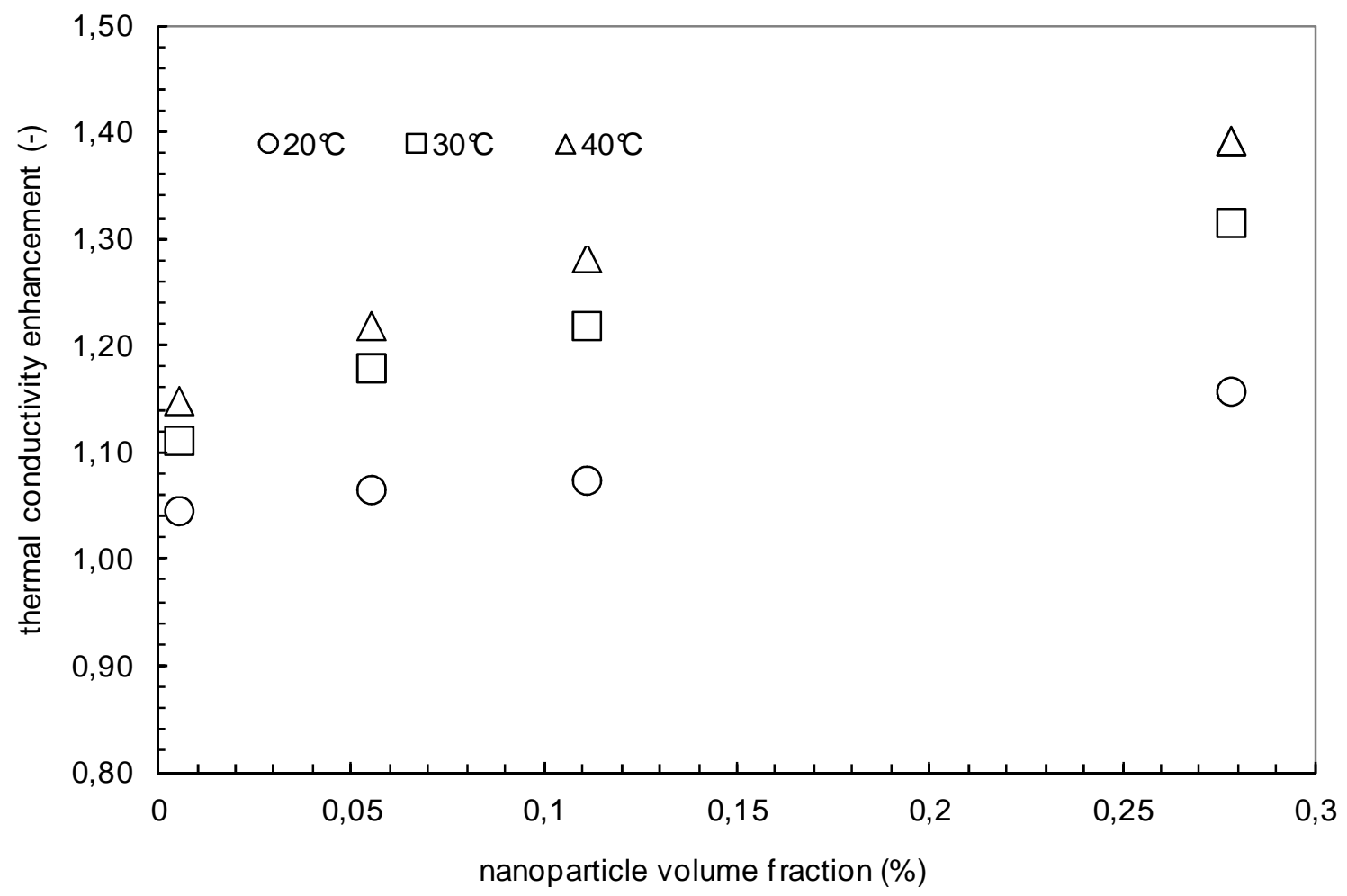

Figure 3. Thermal conductivity enhancement of nanofluids in function of nanoparticle volume fraction and temperature 


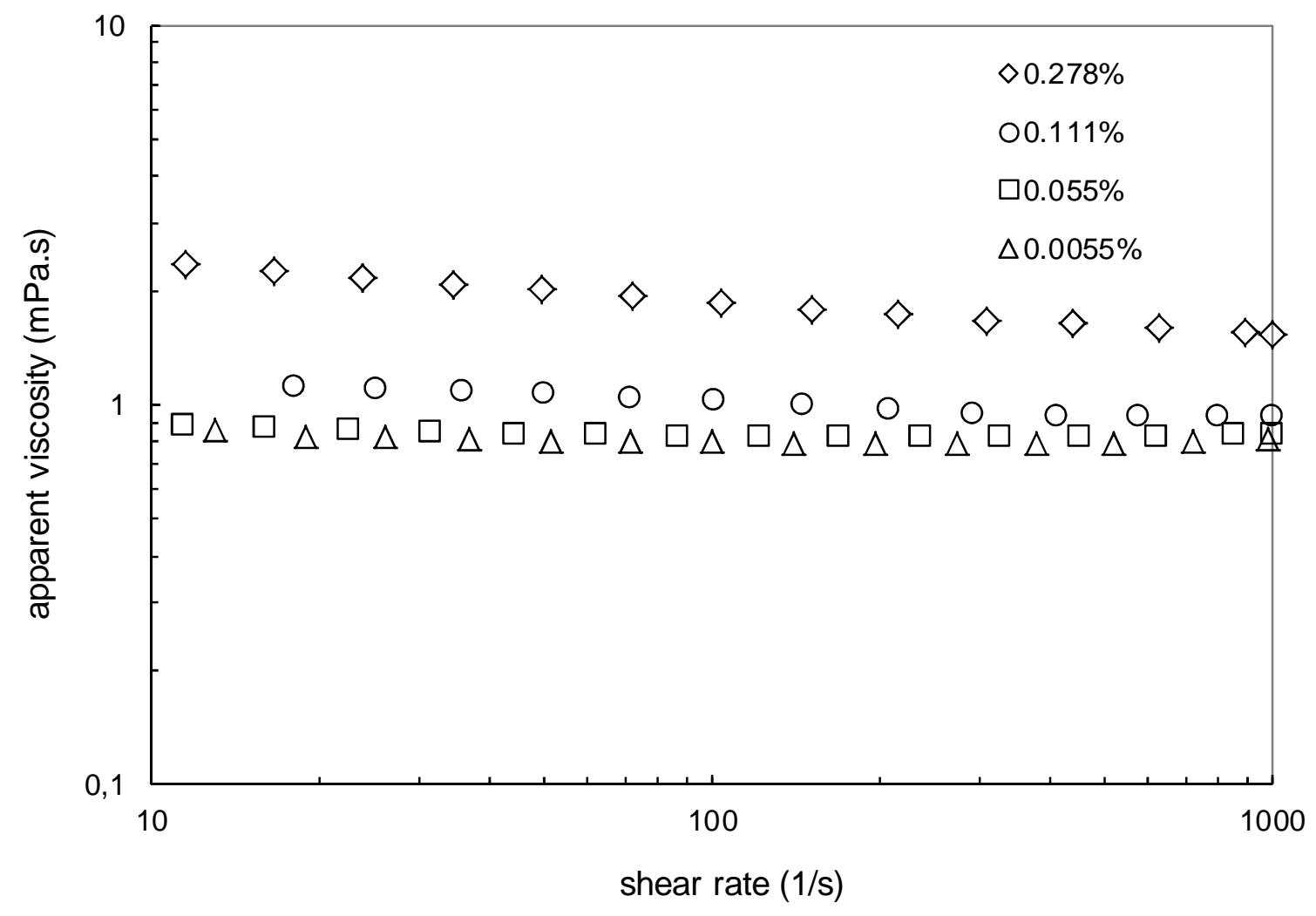

Figure 4. Apparent shear viscosity of nanofluids at $30^{\circ} \mathrm{C}$ 


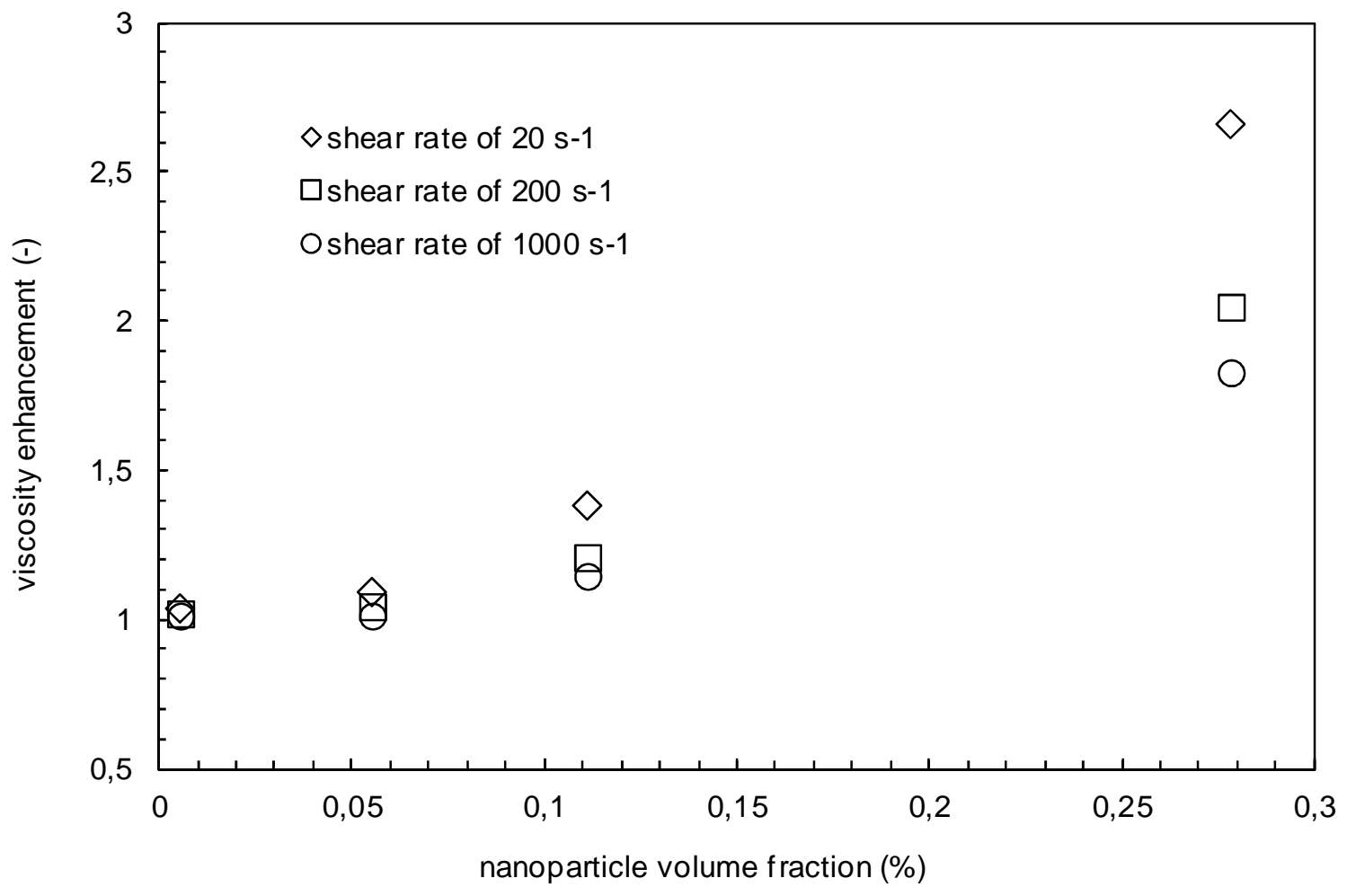

Figure 5. Viscosity enhancement of nanofluids in function of nanoparticle volume fraction and shear rate 


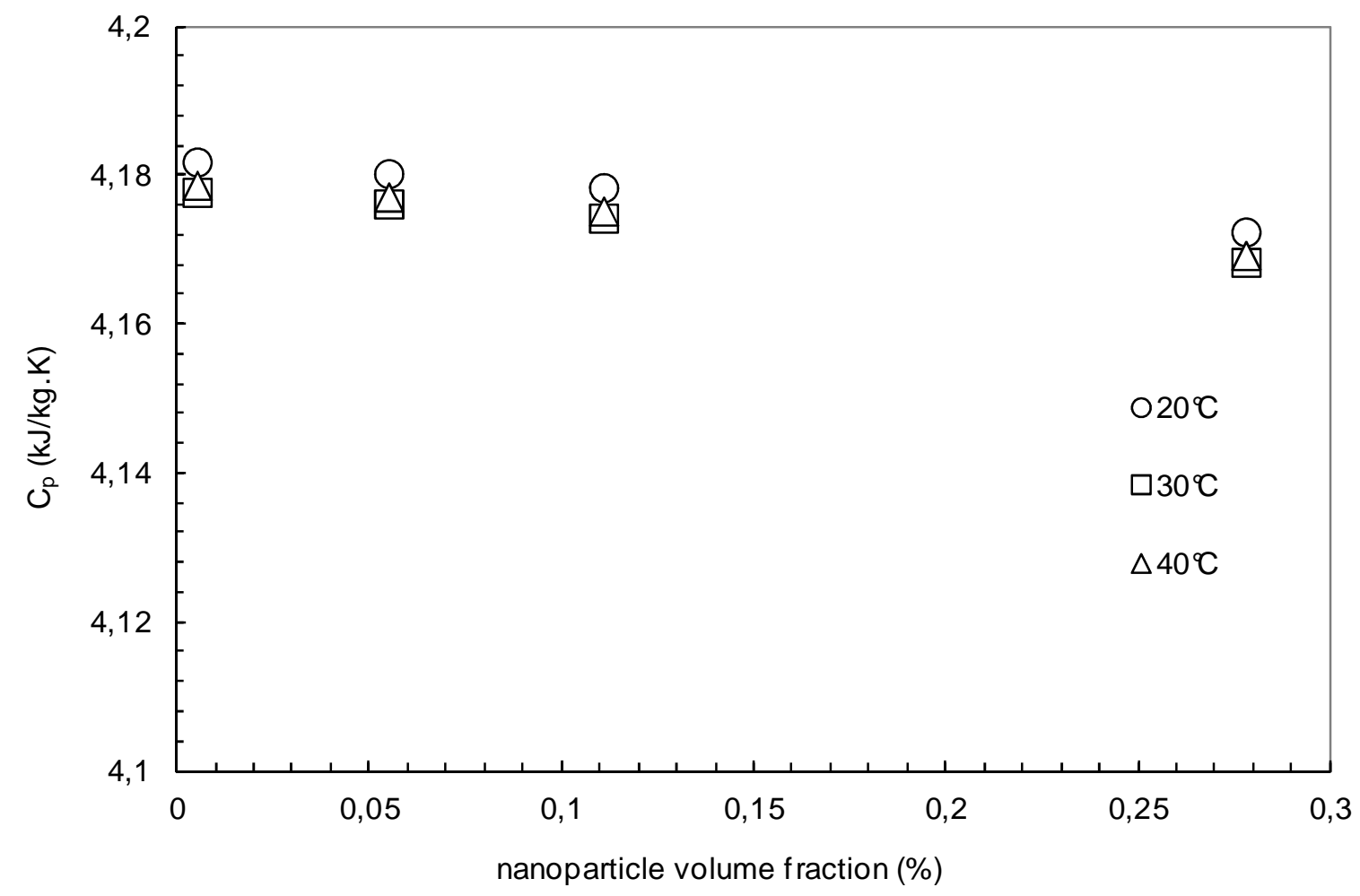

Figure 6. Specific heat of the nanofluids in function of nanoparticle volume fraction and temperature 


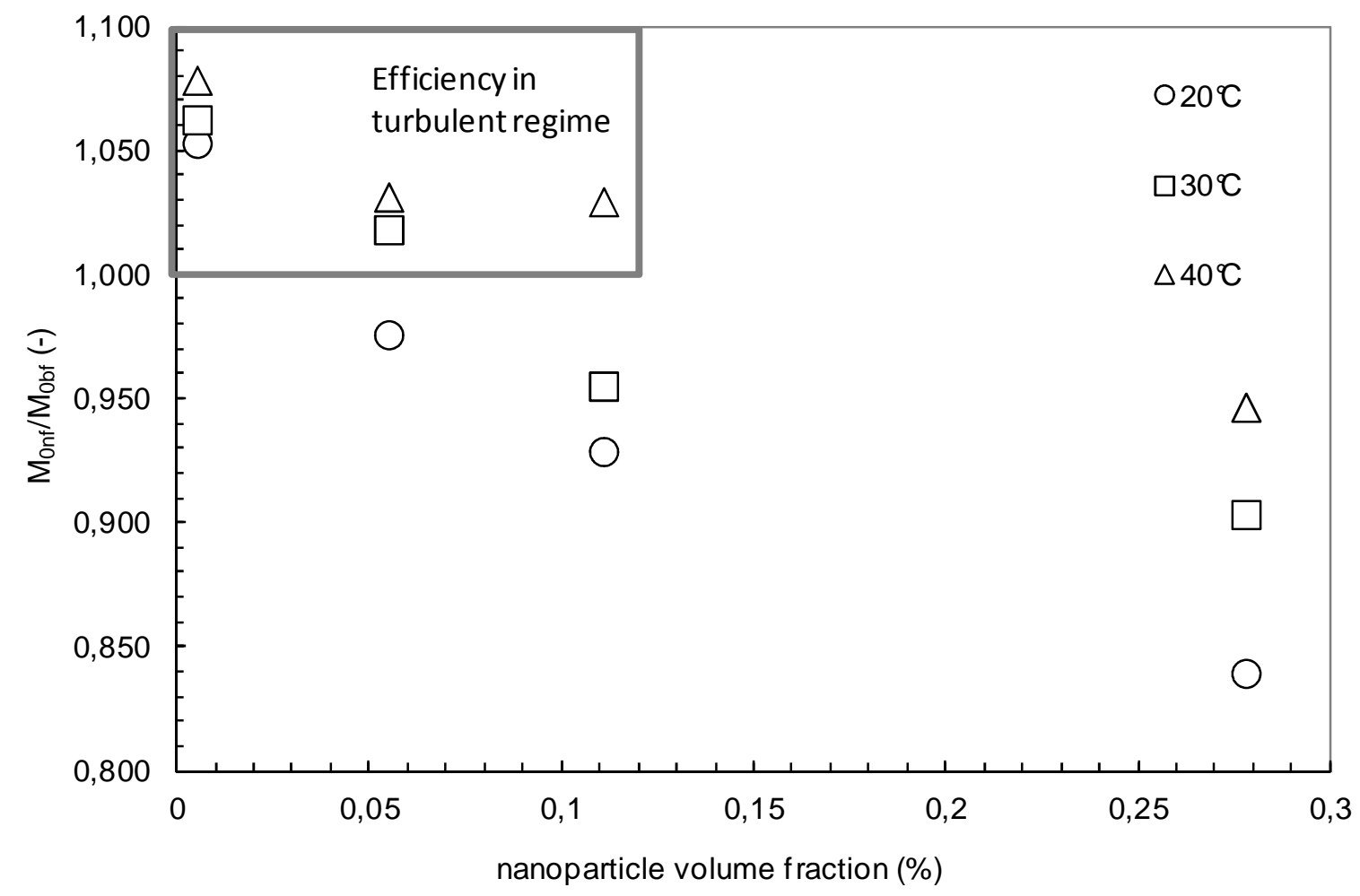

Figure 7. Enhancement of Mouromtseff number of the nanofluids in function of nanoparticle volume fraction and temperature 
Table 1. Reynolds number within the cone and plate geometry for the studied nanofluids: Influence of shear rate, particle content and temperature

\begin{tabular}{c|ccc|ccc|ccc|ccc}
\hline Volume fraction (\%) & \multicolumn{3}{|c|}{0.278} & \multicolumn{3}{|c|}{0.111} & \multicolumn{3}{|c|}{0.055} & \multicolumn{3}{|c}{0055} \\
\hline Temperature $\left({ }^{\circ} \mathrm{C}\right)$ & 20 & 30 & 40 & 20 & 30 & 40 & 20 & 30 & 40 & 20 & 30 & 40 \\
Shear rate of $20 \mathrm{~s}^{-1}$ & 2 & 2.5 & 3.2 & 3 & 5 & 6.5 & 5 & 7 & 8 & 5 & 7 & 9 \\
Shear rate of $200 \mathrm{~s}^{-1}$ & 26 & 30 & 40 & 32 & 59 & 74 & 50 & 70 & 85 & 57 & 70 & 86 \\
Shear rate of $1000 \mathrm{~s}^{-1}$ & 140 & 180 & 230 & 170 & 326 & 400 & 260 & 290 & 430 & 275 & 330 & 450 \\
\hline
\end{tabular}


Table 2. Ratio of viscosity enhancement coefficient to thermal conductivity enhancement coefficient in function of shear rate and temperature

\begin{tabular}{c|ccc}
\hline Temperature $\left({ }^{\circ} \mathrm{C}\right)$ & 20 & 30 & 40 \\
\hline $\mathrm{C}_{\mu} / \mathrm{C}_{\mathrm{k}}$ at $20 \mathrm{~s}^{-1}$ & 13.4 & 7.85 & 6.5 \\
$\mathrm{C}_{\mu} / \mathrm{C}_{\mathrm{k}}$ at $200 \mathrm{~s}^{-1}$ & 8 & 4.71 & 3.88 \\
$\mathrm{C}_{\mu} / \mathrm{C}_{\mathrm{k}}$ at $1000 \mathrm{~s}^{-1}$ & 6.34 & 3.71 & 3.05 \\
\hline
\end{tabular}

